\title{
A New Music Teaching Mode Based on Computer Automatic Matching Technology
}

\author{
https://doi.org/10.3991/ijet.v16i16.24895 \\ Yingxue Zhang, Ding Yi $\left({ }^{\square}\right)$ \\ Hubei Engineering University, Xiaogan, China \\ duzhu2030@163.com
}

\begin{abstract}
The rapidly developing computer technology has been extensively applied in music teaching. The computer automatic matching technology supports the automatic generation of randomized teaching contents, providing a good tool to develop the musical thinking of students. This paper tentatively introduces this technology to music teaching, and derives a new music teaching mode. The results show that, computer technology can effectively assist in music teaching; the inclusion of computer technology in music teaching arouses students' interest in music activities; the application of computer automatic matching technology has improved students' professional skills, live music performance, as well as music ability. The research results greatly promote the reform of music teaching modes and methods.
\end{abstract}

Keywords - computer technology, music teaching, computer automatic matching technology, teaching mode, music activities

\section{Introduction}

Art education is an important means of quality education, and music lessons are quite popular among students [1,2]. As computer technology is developing and maturing constantly, its application in education has received more attention and has played a significant promotive role in education [3]. With the deepening of the integration of information technology and education system, current research has found that information technology also has a positive role in music teaching $[4,5]$. The promotion of computer technology enables us to complete teaching works that were difficult to complete in the past, and it accelerates the update of teaching concepts and teaching methods, thereby improving the quality of classroom teaching $[6,7]$.

Music teaching closely keeps up with the pace of the times, and students' familiarization with computer technology is corresponding to its application in music teaching [8]. Some scholars found that teachers in charge of teaching professional music skills generally have strong awareness to make use of the information technology $[9,10]$. The PPT documents made by these teachers generally focus on the integration of computer technology and music teaching, they took computer technology as the tool for cognition and emotion motivation and use it to encourage students to conduct autonomous learning and share the learning resources. Many Chinese colleges and 
universities have invented a few IT-based music tools for music teaching, such as voice training programs, tuning devices, tuning software, and song accompaniment tapes [11]. In terms of IT application in music teaching, China started late, and the main applications right now are mainly limited to music appreciation and music composition $[12,13]$.

Computer automatic matching technology can realize automatic matching of existing information of related subjects [14]. In terms of music teaching, if the computer automatic matching technology is applied to music teaching, it could realize automatic matching of music background, music melody, composition, and lyrics, etc. [15, 16], and the automatic matching information library will be constantly updated with the emergence of new technologies or new materials [17]. The traditional application of computer technology in teaching is that teachers give demonstrations according to preset contents or programs, which cannot be adjusted flexibly with the changes in the classroom, resulting in that students' thinking is limited within the range of the existing content [18]. When we introduce computer automatic matching technology into teaching, some teaching results might be different from reality, however, it can promote students to think and exercise independently by themselves [19, 20]. This paper aims to explore the application of computer automatic matching technology in music teaching and study a new music teaching mode, in the hopes of greatly promoting the reform of music teaching modes and methods.

\section{$2 \quad$ Application of computer technology in music teaching}

\subsection{Problems in the application of computer technology in music class}

The different stimuli acting on the sense organs of human body form the memory formation process of human brain. Figure 1 shows the process of memory formation. Through different stimuli from multiple organs and the classroom communication between teachers and students, students' ability to acquire knowledge can be greatly improved. However, the features of computer technology can well adapt to music teaching and improve the quality of teaching [21]. At present, the development of computer technology makes it more convenient for teachers and students to use network resources, and the resources available for teaching have been greatly increased $[22,23]$. Figure 2 lists the advantages of the application of computer technology in music class. The application of computer technology can improve the teaching efficiency of music class, increase creation methods, the computer-aided music technology can diversify music teaching and creation methods, the initiative of music creation can be significantly improved, students' music creation ability could be improved, and they can use computer technology to display the music works in more diverse ways such as notation, performance, and simple accompaniment, etc.

At present, computer technology can indeed significantly improve music teaching ability, especially the music creation teaching ability, however, there're a few drawbacks [24]. Figure 3 lists a few problems with the application of computer technology in music class. First, it ignores the notation learning of students, they always use 
computer software to convert notation into drawing melody lines, which has weakened the notation training and learning of students; second, students are prone to develop the habit of relying on computer software in the creation process, in the long run, this would harm the formation of their basic music creation skills; third, lack of computer knowledge, many teachers and students are rusty with computer technology, so the advantages of computer technology in music teaching cannot be fully exerted; fourth, unsound curriculum system, a good curriculum system can greatly promote music teaching works, however, the music curriculum system in ordinary higher-educational schools needs to be improved; fifth, many teachers are not familiar with the music software and techniques, and few attention has been paid to this aspect. Figure 4 lists a few problems in music teaching. The teaching methods need to be enriched, the teaching effect needs to be improved, the creative thinking is weak, and the teaching relies too much on existing teaching resources.

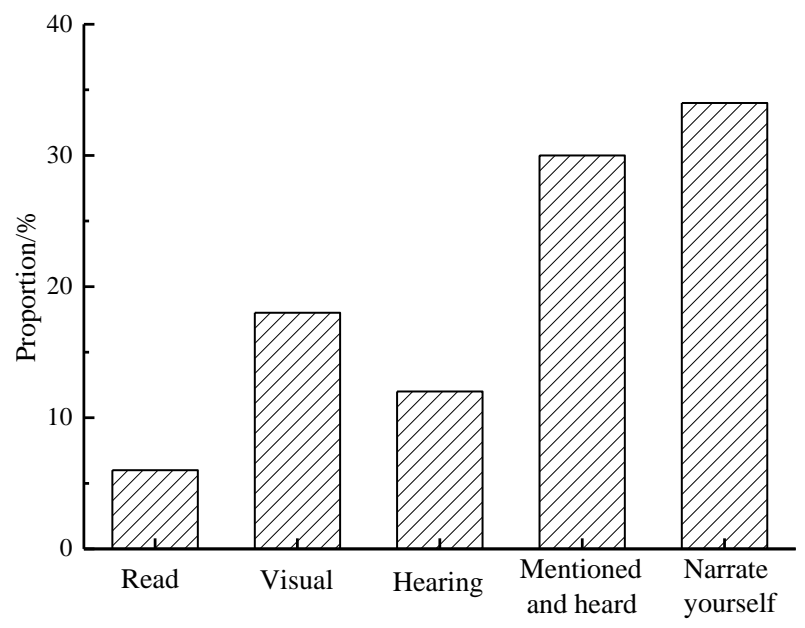

Fig. 1. Process of human memory formation

\begin{tabular}{|c|c|}
\hline $\begin{array}{c}\text { The advantages of } \\
\text { computer technology } \\
\text { in music classroom }\end{array}$ & Teaching efficiency is improved \\
\hline Music creation methods have increased \\
\hline Significantly improved music creation \\
initiative
\end{tabular}

Fig. 2. Advantages of the application of computer technology in music class 


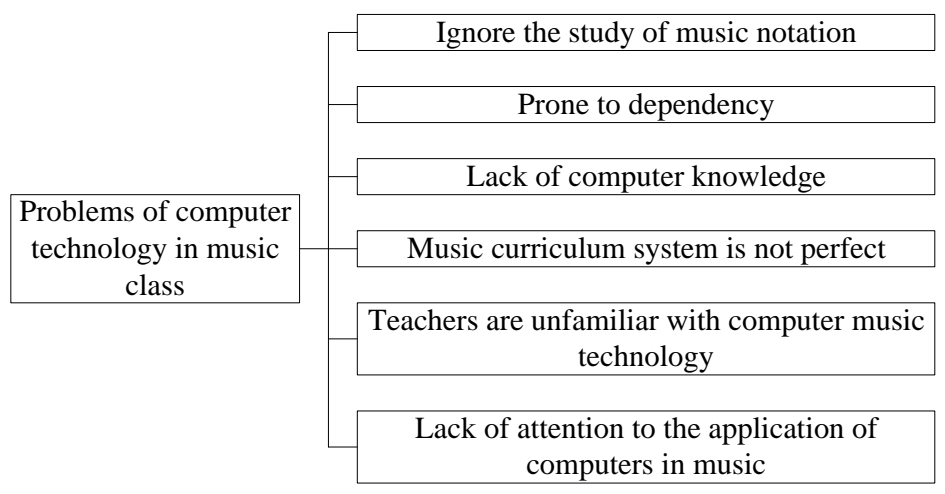

Fig. 3. Problems with the application of computer technology in music class

\begin{tabular}{|c|}
\hline $\begin{array}{c}\text { Single teaching method needs to be enriched } \\
\text { Problems faced } \\
\text { by music } \\
\text { teaching }\end{array}$ \\
\hline $\begin{array}{c}\text { Teaching effect needs to be improved } \\
\text { One-sided dependence on existing teaching } \\
\text { resources }\end{array}$ \\
\hline
\end{tabular}

Fig. 4. Problems in music teaching

\subsection{Countermeasures for the application of computer technology in music class}

Computer technology is an assistant means for music teaching, and it is also a medium of communication between teachers and students during music teaching [25, 26]. If teachers could apply information technology based on actual teaching conditions, it'll greatly improve the quality of music teaching [27, 28]. Figure 5 lists a few countermeasures for the application of computer technology in music class. First, improve the computer skills of music teachers, improve their ability to use computer technology in teaching design, and give personalized computer software training to some teachers. Second, enrich the application methods of computer technology in music teaching, and use computer technology to allow students to understand music and improve their musical skills through multiple channels, students can also use computer technology and the Internet to obtain information under the guidance of teachers, and learn the relevant content through independent learning or collaborative learning. Third, we need to do a good job in developing and sharing music teaching resources, and encouraging and instructing students to learn independently, we also need to do a good job in resource sharing via computer technology environment, building music teaching resource library with the help of computer technology, and 
collecting and storing audio materials related to music teaching [29]. Fourth, well design and share the micro-classes and use them to give explanations, demonstrations, and repeat singing in the music teaching process [30]. Fifth, perfect the curriculum system of creative music teaching, diversify the application methods of computer technology in music teaching, expand the modes and methods of traditional classroom education, and cultivate students' musical quality and innovation ability.

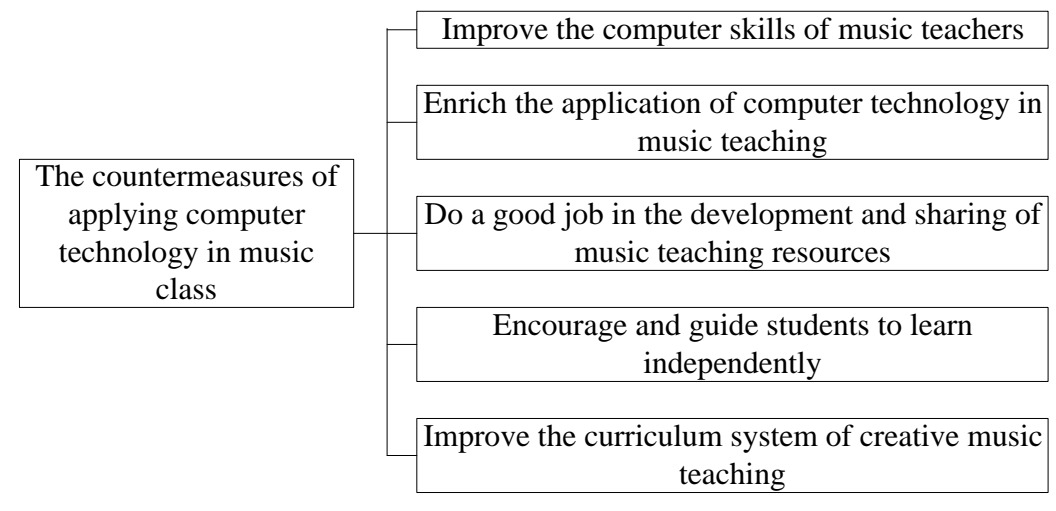

Fig. 5. Countermeasure for applying computer technology in music class

\section{Current status of the application of computer technology in music teaching}

The versatility of computer technology enables music teaching to express in richer and more colorful forms. The processes of music appreciation, music singing, music dance and music creation can achieve their respective teaching goals through computer technology [31, 32]. Multimedia teaching methods generally contain much audiovisual effects and corresponding audio-visual technologies, which can better break through the time and space limitations of traditional classroom and bring more musical forms to the class [33, 34]. During the teaching of "Music Appreciation", using too much computer technology would make us ignore the teaching goals, in terms of teaching effect, although the classroom atmosphere seems quite lively, the actual teaching effect is not good; moreover, the role of teachers and students has been ignored as well, too much introduced content would make it hard for students to learn the relevant music knowledge, resulting in teachers are in a completely passive position. During the teaching of "Music Singing", few attentions have been paid to the application of computer technology, and it failed to well mobilize the atmosphere of music classroom. College students generally have certain basic music knowledge, however, for many ordinary middle school students, their basic music knowledge is poor, their pitch is poor, and their sense of rhythm is poor; without basic music teaching equipment and facilities, it's difficult to arouse students' enthusiasm for music class [35]. During the teaching of "Music Dance", the application of computer technology failed to reflect the beauty of dance, and the application of computer technol- 
ogy in dance teaching needs to be further improved. During the teaching of "Music Creation", due to the limitation of music creation conditions, there're many defects with the application of computer technology in music teaching, in the process of music creation, the application of computer technology in music teaching also requires teachers to be able to deal with unexpected teaching situations.

Figure 6 shows statistics of students' understanding of the application of computer technology in music teaching. Only $50 \%$ of middle school students are familiar with or have certain understanding of the computer technology, and $6.25 \%$ of middle school students are not familiar with computer. Figure 7 shows the proportions of computer technology application in various music classes. According to the statistics, piano lessons are the music class type that makes use of the computer technology the most, and this indicates that computer technology has the biggest room for application in piano skill teaching class. Figure 8 lists the value of introducing computer technology into music class. The introduction of computer technology into music teaching could arouse students' interest to participate in music activities.

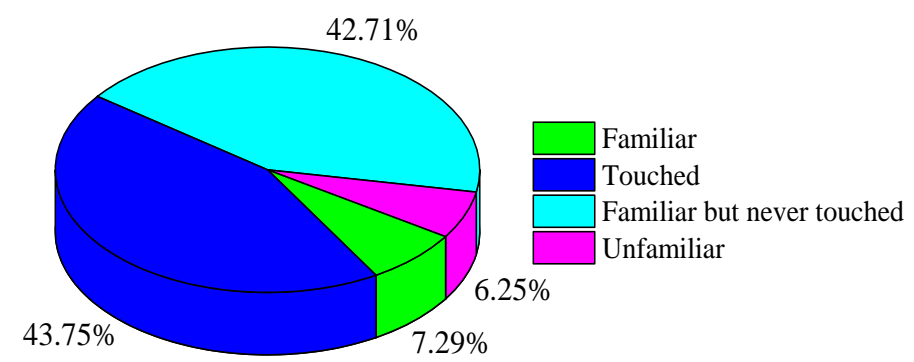

Fig. 6. Statistics of students' understanding of the application of computer technology in music teaching

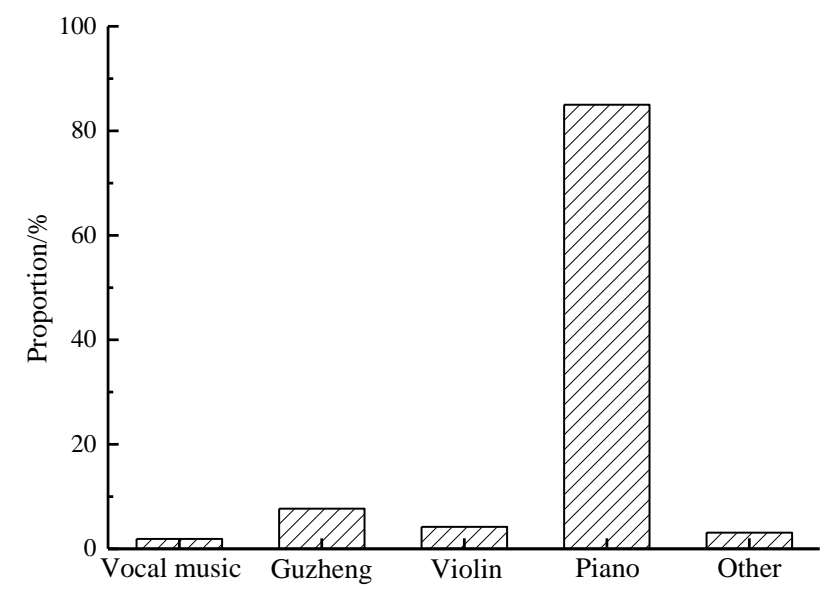

Fig. 7. Proportions of computer technology application in various music classes 


\begin{tabular}{|c|c|}
\hline $\begin{array}{c}\text { The value of introducing } \\
\text { computer technology into } \\
\text { music classes }\end{array}$ & $\begin{array}{c}\text { Enrich the interest of theoretical knowledge } \\
\text { Computer technology facilitates access to } \\
\text { music resources on the spot }\end{array}$ \\
\hline $\begin{array}{c}\text { Computer technology facilitates musical } \\
\text { arrangement and rhythm practice }\end{array}$ \\
\hline Create a beautiful teaching environment \\
\hline
\end{tabular}

Fig. 8. Value of introducing computer technology into music class

\section{Music teaching mode based on computer automatic matching technology and case study}

\subsection{Reform of music teaching mode}

The modern education technology represented by the computer technology has greatly expanded the capacity of music teaching, enriched teaching methods and teaching resources, therefore it has a very broad application prospects in music education. The computer automatic matching technology can quickly and accurately match the information required by teachers in the application process, and can realize the music's creative development value as proposed in the new curriculum. The current music teaching in colleges and universities is the teacher-led music teaching mode, which is mostly used for the training of musical skills, in fact, the demonstrations given by teachers could be performed using the computer technology to facilitate students to imitate and practice. Under the impact of music teaching mode reform and new computer technologies, the "dominant-subject" teaching mode centers on the learning development of students during the music teaching practice, under such new music teaching mode, teachers propose questions and guide students to perform activities such as music performance, music creation, music appreciation, and music research, etc.

According to the survey results shown in Figure 7 we can see that piano lessons are the type of music class that makes use of the computer technology the most. Figure 9 shows the statistics of the impact of computer technology application on piano skill learning, it can be clearly seen that the impact of the application of computer technology on the learning of wrong notes is the greatest. Figure 10 lists the advantages of the new music teaching mode. Under such new music teaching mode, the teaching demonstration is more intuitive, students' learning initiative can be improved, it could establish the correct performance techniques and tone concepts for students, and it extends the classroom teaching, and improves students' musical performance ability. 


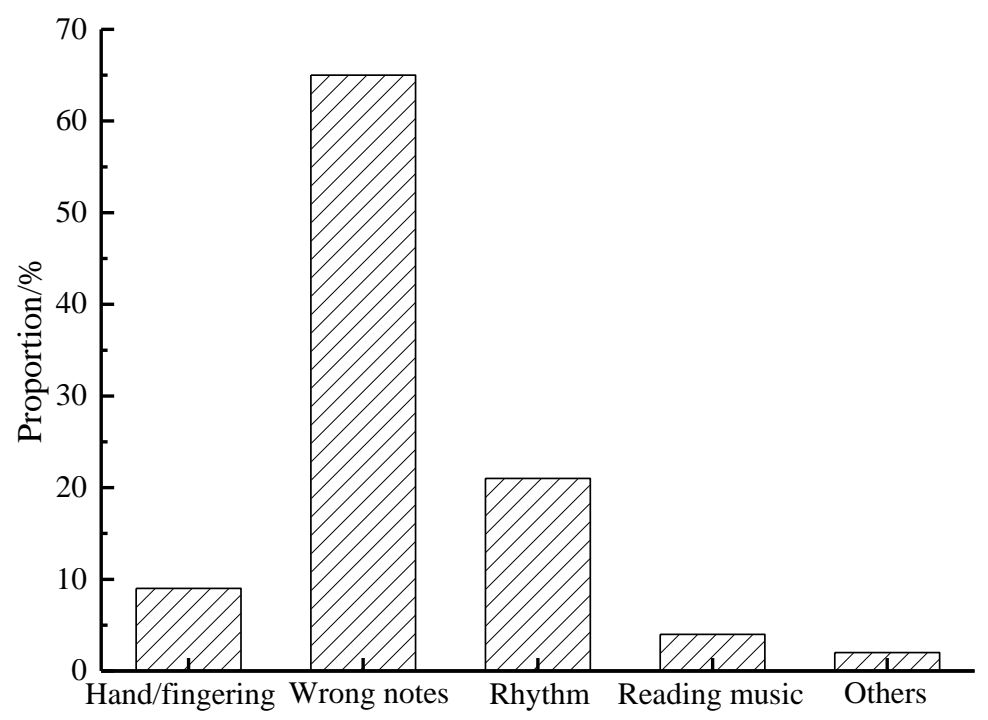

Fig. 9. Statistics of the impact of computer technology application on piano skill learning

\begin{tabular}{|c|c|}
\hline $\begin{array}{c}\text { Teaching demonstration is more intuitive } \\
\text { Advantages of } \\
\text { new music } \\
\text { teaching mode }\end{array}$ \\
\hline Improve students' learning initiative \\
\hline Establish correct performance techniques \\
for students
\end{tabular}

Fig. 10. Advantages of the new music teaching mode

\subsection{Case study of the new music teaching mode based on computer automatic matching technology}

To figure out the impact of computer automatic matching technology on music teaching, through comparison and observation of students' skills, growth, and error rate, the impact of such technology on the teaching results was analyzed. Figure 11 shows the designed teaching process of music class. After preliminary preparations, the computer automatic matching technology was applied to assist the teaching in the traditional classroom, after that, after-class practice was carried out, and again the computer automatic matching technology was adopted for review teaching, then after- 
class practice was carried out again and teachers were asked to give scores. 32 students from Zhejiang Conservatory of Music were taken as research objects and divided into two groups (16 students in each group), the traditional music teaching mode and the new music teaching mode were adopted for music teaching of 4 class hours.

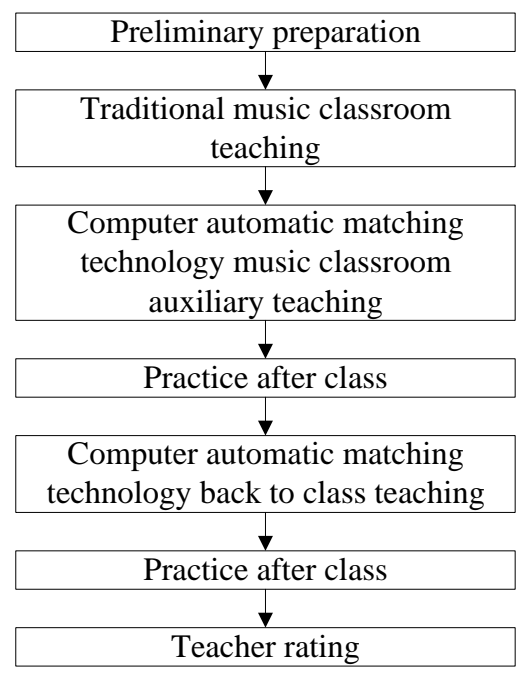

Fig. 11. Designed teaching process of music class

Figure 12 shows the comparison of the two music classes. As can be clearly seen from the figure, the application of computer automatic matching technology had improved the professional skills of students to a certain extent, their assessment scores of live music performance and ability growth were higher. Moreover, under the condition of same learning and assessment content, in the case that the computer automatic matching technology had been applied in music teaching, the error rate was reduced significantly. Figure 13 is a comparison of the scores of four class hours of the two music teaching modes. The application of computer automatic matching technology had greatly improved the effect of music teaching. However, the new music teaching mode based on computer automatic matching technology also needs to take the traditional music teaching mode as the foundation. Only by combining the traditional teaching mode, making continuous efforts to innovate, and overcoming various difficulties, can the music teaching truly make a qualitative leap. 


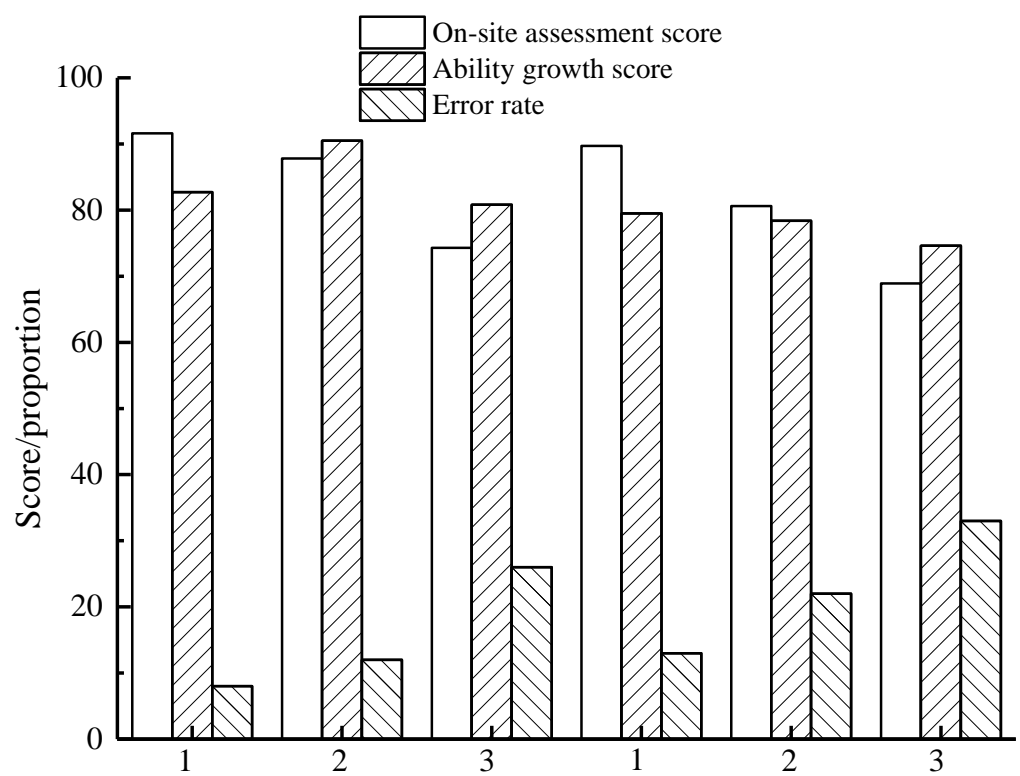

Computer automatic matching technology Traditional music teaching

Fig. 12. Comparison of the two music classes

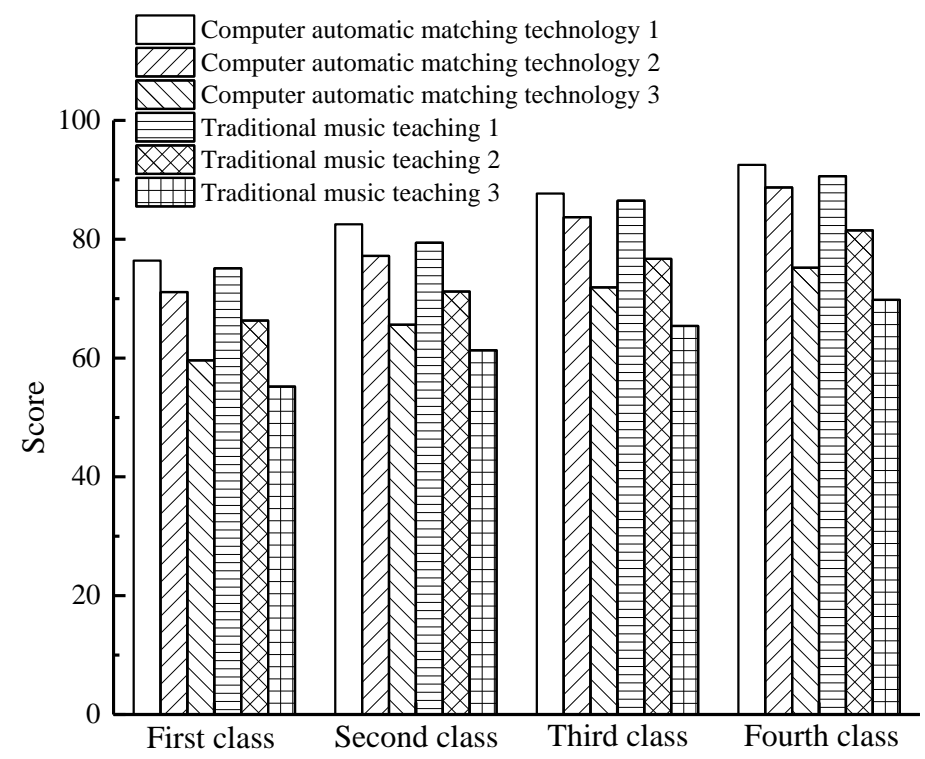

Fig. 13. Comparison of scores of four class hours of the two music teaching modes 


\section{Conclusions}

This paper explored the application of computer automatic matching technology in music teaching and studied a new music teaching mode based on this technology, the specific research conclusions are as follows:

1. The application of computer automatic matching technology in music teaching improved the computer skills of music teachers, enhanced their ability to use computer technology in teaching design, and enriched the application methods of computer technology in music teaching, which is conductive to developing and sharing the music teaching resources and encouraging and instructing students to learn independently.

2. Under the impact of music teaching mode reform and new computer technologies, the "dominant-subject" teaching mode centers on the learning development of students during the music teaching practice, under such new music teaching mode, teachers propose questions and guide students to perform activities such as music performance, music creation, music appreciation, and music research, etc.

3. The application of computer automatic matching technology had improved the professional skills of students to a certain extent, their assessment scores of live music performance and ability growth were higher. In addition, the application of computer automatic matching technology had greatly improved the effect of music teaching.

\section{$6 \quad$ References}

[1] Kong, F.W. (2020). Evaluation model of adaptive teaching ability of college art teachers. International Journal of Emerging Technologies in Learning, 15(9), 143-155. https://doi.org/10.3991/ijet.v15i09.14031

[2] Thu, N.T.H. (2020). Communication skills and reflection practice in smart english teaching and learning environment: A case study. International Journal of Emerging Technologies in Learning, 15(17), 221-237. https://doi.org/10.3991/ijet.v15i17.15235

[3] Jayakumar, P., Padmanabhan, S, Suthendran, K., Rajveer, G.V. (2020). Development of safe semi-automatic and economic blood cross matching using image processing. Materials today: proceedings, 44(5): 3536-3539. https://doi.org/10.1016/j.matpr.2020 .09 .293

[4] Zhao, Y., Zhao, C. (2019). Research on college english teaching model under the computer environment. Social Networking, 8(2): 104-111. https://doi.org/10.4236/sn.2019.82007

[5] Mohammadzadeh, M. (2020). Exploring tertiary students' travel mode choices in auckland: insights and policy implications. Journal of Transport Geography, 87: 102788. https://doi.org/10.1016/j.jtrangeo.2020.102788

[6] Ge, L., Zhu, Z., Yu, Q., Wan, H. (2013). Exploration on student-centered fermentation engineering course by problems conducted teaching. Creative Education, 4(2): 89-91. https://doi.org/10.4236/ce.2013.42012

[7] Prinsloo, P., Van Rooyen, A.A. (2007). Exploring a blended learning approach to improving student success in the teaching of second year accounting. Meditari Accountancy Research, 15(1): 51-69. https://doi.org/10.1108/10222529200700004 
[8] Oguz, K., Dagdeviren, Z.A., Cinsdikici, M.G. (2014). Three techniques for automatic extraction of corpus callosum in structural midsagittal brain mr images: valley matching, evolutionary corpus callosum detection and hybrid method. Engineering Applications of Artificial Intelligence, 31: 101-115. https://doi.org/10.1016/j.engappai.2013.10.004

[9] Choi, H., Bindschadler R. (2004). Cloud detection in landsat imagery of ice sheets using shadow matching technique and automatic normalized difference snow index threshold value decision. Remote Sensing of Environment, 91(2): 237-242. https://doi.org/10.1016 /j.rse.2004.03.007

[10] Kuss, E., Leopold, H., Han, V., Stuckenschmidt, H., Reijers, H.A. (2018). A probabilistic evaluation procedure for process model matching techniques. Data \& Knowledge Engineering, 117: 393-406. https://doi.org/10.1016/j.datak.2018.04.008

[11] O'Connor, P., Barker, K. (2020). Automatic matching using intraprostatic calcifications as a volume of interest in cbct images during prostate radiotherapy: a comparative study. Journal of Radiotherapy in Practice, 19(2): 108-111. https://doi.org/10.1017/S14603969 19000529

[12] Neto, F.D.N., de Souza Baptista, C., Campelo, C.E. (2018). Combining Markov model and prediction by partial matching compression technique for route and destination prediction. Knowledge-Based Systems, 154: 81-92. https://doi.org/10.1016/j.knosys.2018.05.007

[13] Tahirolu, K., Magnusson, T., Parkinson, A., Garrefls, I., Tanaka, A. (2020). Digital musical instruments as probes: how computation changes the mode-of-being of musical instruments. Organised Sound, 25(2): 269-269. https://doi.org/10.1017/S135577181900 $\underline{0475}$

[14] Pohjannoro, U., Rousi, A.M. (2018). The modes of music information in a compositional process: a case study. Journal of Documentation, 74(5): 987-1007. https://doi.org /10.1108/JD-10-2017-0141

[15] Rousi, A.M., Savolainen, R., Harviainen, M., Vakkari, P. (2018). Situational relevance of music information modes: an empirical investigation among doctor of music students. Journal of Documentation, 74(5): 1008-1024. https://doi.org/10.1108/JD-10-2017-0149

[16] Biasutti, M. (2015). Creativity in virtual spaces: Communication modes employed during collaborative online music composition. Thinking skills and creativity, 17: 117-129. https://doi.org/10.1016/j.tsc.2015.06.002

[17] Erdal, G.G. (2015). The heritage central asian turkish music culture left to anatolian music culture: similar elements in central Asian-Anatolian Turkish music cultures. Procedia Social and Behavioral Sciences, 174: 2983-2988. https://doi.org/10.1016/j.sbspro. 2015.01.1038

[18] Custodero, L.A., Johnson-Green, E.A. (2003). Passing the cultural torch: musical experience and musical parenting of infants. Journal of Research in Music Education, 51(2): 102-114. https://doi.org/10.2307/3345844

[19] Wielfrid, M.M., Iza, M.S., Tra, G.B. (2020). Information extraction model to improve learning game metadata indexing. Ingénierie des Systèmes d'Information, 25(1), 11-19. https://doi.org/10.18280/isi.250102

[20] McCoid, S., Freeman, J., Magerko, B., Michaud, C., Jenkins, T., Mcklin, T., Kan, H. (2013). EarSketch: An integrated approach to teaching introductory computer music. Organised Sound, 18(2): 146-160. https://doi.org/10.1017/S135577181300006X

[21] Truman, P.J. (2010). An investigation of the situated learnability effects of single- and dual-modal systems in education: a report of music-oriented learning environment and science computer-assisted teaching studies. British Journal of Educational Technology, 37(1): 131-142. https://doi.org/10.1111/j.1467-8535.2005.00533.x 
[22] Li, S.L., Chai, H.Q. (2021). Recognition of teaching features and behaviors in online open courses based on image processing. Traitement du Signal, 38(1), 155-164. https://doi.org/ $\underline{10.18280 / \text { ts. } 380116}$

[23] Wijaya, M.C. (2020). Two stages best first search algorithm using hard and soft constraints heuristic for course timetabling. Revue d'Intelligence Artificielle, 34(4), 413-418. https://doi.org/10.18280/ria.340405

[24] Xia, Y. (2020). Resource scheduling for piano teaching system of internet of things based on mobile edge computing. Computer Communications, 158: 73-84. https://doi.org/ $\underline{10.1016 / j . c o m c o m .2020 .04 .056}$

[25] Baratè, A., Ludovico, L.A., Malchiodi, D. (2017). Fostering computational thinking in primary school through a LEGO®-based music notation. Procedia Computer Science, 112: 1334-1344. https://doi.org/10.1016/j.procs.2017.08.018

[26] Ferguson, J., Brown, A.R. (2016). Fostering a Post-Digital Avant-Garde: Research-led teaching of music technology. Organised Sound, 21(2): 127-137. https://doi.org/10.1017 /s1355771816000054

[27] Borges, J.A., Tomé, D. (2014). Teaching music to blind children: new strategies for teaching through interactive use of musibraille software. Procedia Computer Science, 27(27): 19-27. https://doi.org/10.1016/j.procs.2014.02.004

[28] Streeter, E., Davies, M., Reiss, J. D., Hunt, A., Roberts, C. (2012). Computer aided music therapy evaluation: testing the music therapy logbook prototype 1 system. Arts in Psychotherapy, 39(1), 1-10. https://doi.org/10.1016/j.aip.2011.11.004

[29] Hewitt, A. (2008). Children's creative collaboration during a computer-based music task. International Journal of Educational Research, 47(1): 11-26. https://doi.org/10.1016/j.ijer .2007 .11 .003

[30] Abo-Ismail, A. (2013). Quality Education in Graduate Mechatronics Programs at EgyptJapan University of Science and Technology. Procedia-Social and Behavioral Sciences, 106: 2179-2188. https://doi.org/10.1016/j.sbspro.2013.12.248

[31] Valckx, J., Vanderlinde, R., Devos, G. (2021). Measuring and exploring the structure of teachers' educational beliefs. Studies in Educational Evaluation, 70: 101018. https://doi .org/10.1016/j.stueduc.2021.101018

[32] Pektas, S.T. (2012). The blended design studio: An appraisal of new delivery modes in design education. Procedia-Social and Behavioral Sciences, 51: 692-697. https://doi.org/ $\underline{10.1016 / j . s b s p r o .2012 .08 .226}$

[33] Munyoka, W. (2014). Evaluation impact of tele-education as new open distance learning delivery mode on learners in Botswana. Procedia-Social and Behavioral Sciences, 116: 1248-1252. https://doi.org/10.1016/j.sbspro.2014.01.377

[34] Vanchukhina, L., Leybert, T., Rogacheva, A., Rudneva, Y., Khalikova, E. (2019). New model of managerial education in technical university. International Journal of Educational Management, 33(3): 511-524. https://doi.org/10.1108/IJEM-08-2018-0270

[35] Wolmarans, H.P. (2019). Postgraduate education in taxation by means of a flexible learning model: A new educational paradigm. Meditari Accountancy Research, 9(1): 333349. https://doi.org/10.1108/1022252920010018

\section{$7 \quad$ Authors}

Yingxue Zhang, female, received Bachelor of Arts degree from Academy of $\mathrm{Mu}-$ sic Hubei Engineering University in 2010 and received Master of Engineering in Software Engineering from the Software College of Huazhong University of Science 
and Technology in 2015. Now she works in Hubei Engineering University as a lecturer. Her main research directions contain Computer Music and Multimedia Vocal Analysis (Email: lzkity123@163.com)

Ding Yi, male, received Bachelor of Management from Law \& Business college of Hubei University of Economics in 2010 and received a master's degree in law from Chongqing University of Posts and Telecommunications in 2013. Now he works in Hubei Engineering University. His main research direction is business management (Email: duzhu2030@163.com)

Article submitted 2021-06-18. Resubmitted 2021-07-19. Final acceptance 2021-07-23. Final version published as submitted by the authors. 